\title{
Trigeminal Ophthalmic Branch Schwannoma: Case Report and Literature Review
}

\section{Schwannoma trigeminal de ramo oftálmico: Relato de caso e revisão da literatura}

\author{
Luiza Rech Köhler ${ }^{1,2}$ Paulo Moacir Mesquita Filho ${ }^{1,2,3,4}$ Fabio Pires Santos ${ }^{1,5}$ Renato Sawasaki ${ }^{6(0)}$ \\ Richard Giacomelli2,7@ Rafael Cordeiro ${ }^{2,7}$ Octavio Karam Ruschel ${ }^{2,7}$ Daniela Schwingel $^{8(1)}$
}

\footnotetext{
${ }^{1}$ Medical School, Universidade de Passo Fundo, Passo Fundo, RS, Brazil

${ }^{2}$ Academic League of Neurology and Neurosurgery Service (LASNN), Passo Fundo, RS, Brazil

${ }^{3}$ Neurology and Neurosurgery Service (SNN), Passo Fundo, RS, Brazil

${ }^{4}$ Department of Neurosurgery, Hospital de Clínicas de Passo Fundo, Passo Fundo, RS, Brazil

${ }^{5}$ ENT surgeon, Hospital de Clínicas de Passo Fundo, Passo Fundo, RS, Brazil

Arq Bras Neurocir 2021;40(1):91-96.
}

\author{
Address for correspondence Luiza Rech Köhler, Departamento de \\ Neurocirurgia, Hospital de Clínicas de Passo Fundo, Rua Tiradentes, \\ 295, Passo Fundo, RS, 99010-260, Brazil \\ (e-mail: luiza_kohler@hotmail.com). \\ ${ }^{6}$ Department of Oral and Maxillofacial Surgery, Hospital de Clínicas de \\ Passo Fundo, RS, Brazil \\ ${ }^{7}$ Hospital de Clínicas de Passo Fundo, RS, Brazil \\ 8 Instituto de Patologia de Passo Fundo, Passo Fundo, RS, Brazil
}

\author{
Abstract \\ Keywords \\ - schwannoma \\ - orbital schwannoma \\ - ophthalmic \\ schwannoma \\ - endoscopic \\ transsphenoidal \\ neurosurgery \\ - subciliary approach
}

\section{Resumo}

\section{Palavras-chave}

- schwannoma

- schwannoma orbital

- schwannoma oftálmico

- neurocirurgia endoscópica Transesfenoidal

- abordagem subciliar
Schwannomas are the fourth most common primary neoplasms affecting the brain and cranial nerves. Central lesions commonly arise from sensory nerve roots, and a common intracranial site is the vestibular branch of the $8^{\text {th }}$ nerve $(>85 \%)$. We present the case report of a patient who has a schwannoma extending from the pterygopalatine fossa to the orbit, complaining about facial pain in the trajectory of the trigeminal ophthalmic branch. Schwannomas represent 1 to $2 \%$ of all neoplasms of the orbit, and trigeminal schwannomas are extremely rare, accounting for less than $0.5 \%$ of all intracranial tumors.

Schwannomas são a quarta neoplasia primária mais comum que afeta o cérebro e os nervos cranianos. As lesões centrais comumente surgem de raízes nervosas sensitivas, e um sítio intracraniano comum é o ramo vestibular do oitavo nervo (mais de $85 \%$ dos casos). Apresentamos o relato de caso de um paciente portador de schwannoma que se estende da fossa pterigopalatina até a órbita, com queixa de dor facial no trajeto do ramo oftálmico do nervo trigêmeo. Schwannomas representam $1-2 \%$ de todas as neoplasias da órbita e schwannomas trigeminais são extremamente raros, respondendo por menos de $0,5 \%$ de todos os tumores intracranianos. received

May 8, 2020

accepted

August 4, 2020

published online

October 16, 2020
DOI https://doi.org/ 10.1055/s-0040-1718421. ISSN 0103-5355.

\footnotetext{
(c) 2020. Sociedade Brasileira de Neurocirurgia. All rights reserved. This is an open access article published by Thieme under the terms of the Creative Commons Attribution-NonDerivative-NonCommercial-License, permitting copying and reproduction so long as the original work is given appropriate credit. Contents may not be used for commercial purposes, or adapted, remixed, transformed or built upon. (https://creativecommons.org/ licenses/by-nc-nd/4.0/) Thieme Revinter Publicações Ltda., Rua do Matoso 170, Rio de Janeiro, RJ, CEP 20270-135, Brazil
} 


\section{Introduction}

Schwannomas are the fourth most common primary neoplasms affecting the brain and cranial nerves. Central lesions commonly arise from sensory nerve roots, and a common intracranial site is the vestibular branch of the eighth nerve ( $>85 \%$ of central schwannomas and $8-10 \%$ of all intracranial tumors.). ${ }^{1-4}$ We present the case report of a patient who has a schwannoma extending from the pterygopalatine fossa to the orbit, complaining about facial pain in the trajectory of the trigeminal ophthalmic branch. Primary orbital tumors are very rare, with an overall incidence $<1$ per $100,000 /$ year; ${ }^{5}$ schwannomas represent 1 to $2 \%$ of all neoplasms of the orbit, ${ }^{4,6}$ and trigeminal schwannomas are extremely rare, accounting for 0.07 to $0.3 \%$ of all intracranial tumors. ${ }^{7,8}$ The patient usually presents with facial pain, numbness, and paresthesia in the distribution of one or all the divisions of the trigeminal nerve depending on the location of the tumor. ${ }^{7,9,10}$ Magnetic resonance imaging (MRI) is the gold standard for evaluation because of its multiplanar capabilities and better soft-tissue contrast, being useful for planning the surgical approach. ${ }^{7,9}$

\section{Case Report}

A 56-year-old female, diabetic, hypertense, who had a hemorrhagic stroke 7 years ago, sought the emergency service complaining about left hemicranial progressive headache, for 3 years. Neurological exam at the admission showed right spastic hemiparesis, Medical Research Council (MRC) grade III, right hyperreflexia and Wernicke-Mann posture. The patient underwent an MRI, which showed an expansive formation involving the left pterygopalatine fossa and the sphenoid bone, heterogeneously enhanced by gadolinium in T1 sequence, extending to the extraconal lateral region of the left orbit, with a rounded aspect measuring $1.9 \mathrm{~cm}$ in its largest diameter, hyperintense in $\mathrm{T} 2$ and without impregnation by gadolinium (-Fig. 1). The patient underwent a transsphenoidal surgery using an endonasal endoscopic
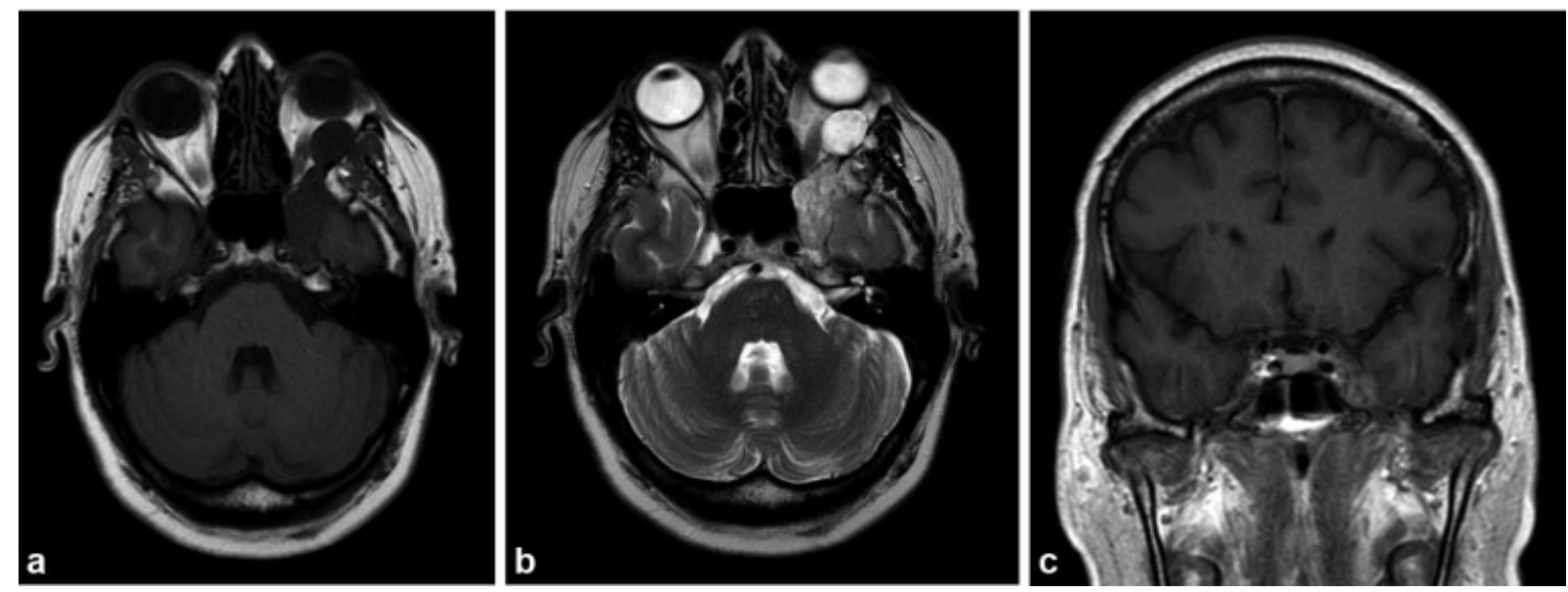

Fig. 1 Preoperative images. (a) Axial T1-weighted gadolinium-enhanced image with a rounded aspect measuring $1.9 \mathrm{~cm}$ in its largest diameter, without impregnation by the gadolinium. (b) Axial T2-weighted image, showing a hyperintense lesion. (c) Coronal T1-weighted gadoliniumenhanced image.
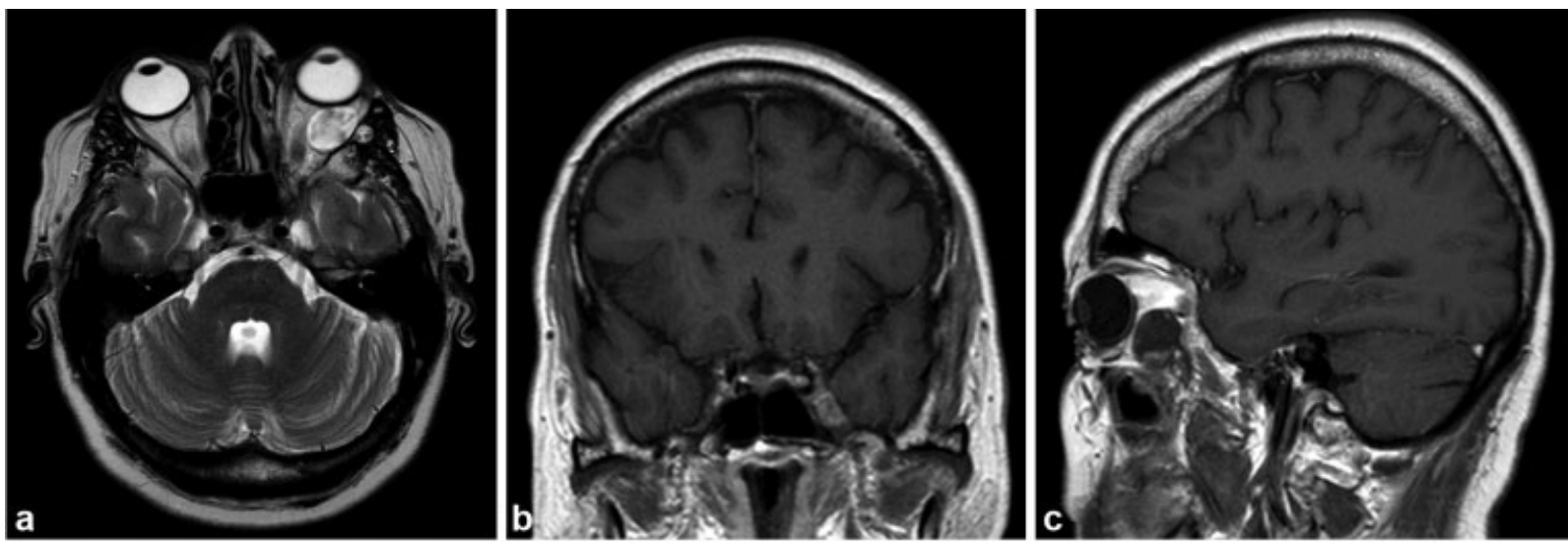

Fig. 2 Postoperative images, after the first surgery. Magnetic resonance imaging still shows an orbital lesion. (a) Axial T2-weighted image, still showing the hyperintense lesion in the extraconal lateral region of the left orbit. (b) Coronal T1-weighted gadolinium-enhanced image, showing the resection performed in the first surgery. (c) Sagittal T1-weighted gadolinium-enhanced image from tumor, measuring $1.9 \mathrm{~cm}$ in its largest diameter, without impregnation by the gadolinium. 

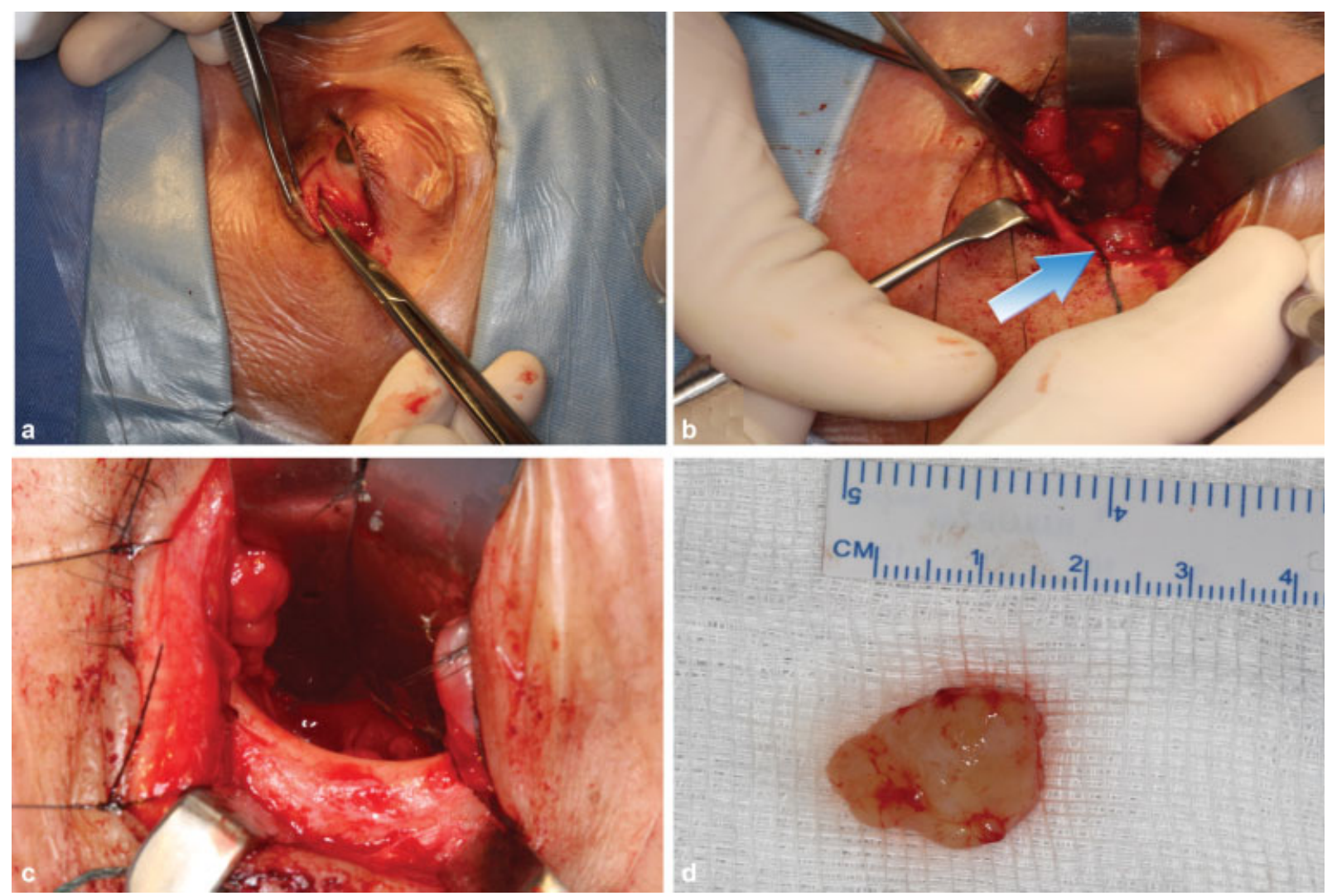

Fig. 3 Intraoperative images, from the second surgical procedure for resection of the orbital portion of the tumor. (a) Transconjunctival approach. (b) Lesion exposure (blue arrow) with partial resection (c) Revision of the tumor cavity evidencing complete resection of the tumor. (d) Surgical specimen measuring $1.8 \mathrm{~cm} \times 1.2 \mathrm{~cm} \times 0.5 \mathrm{~cm}$.
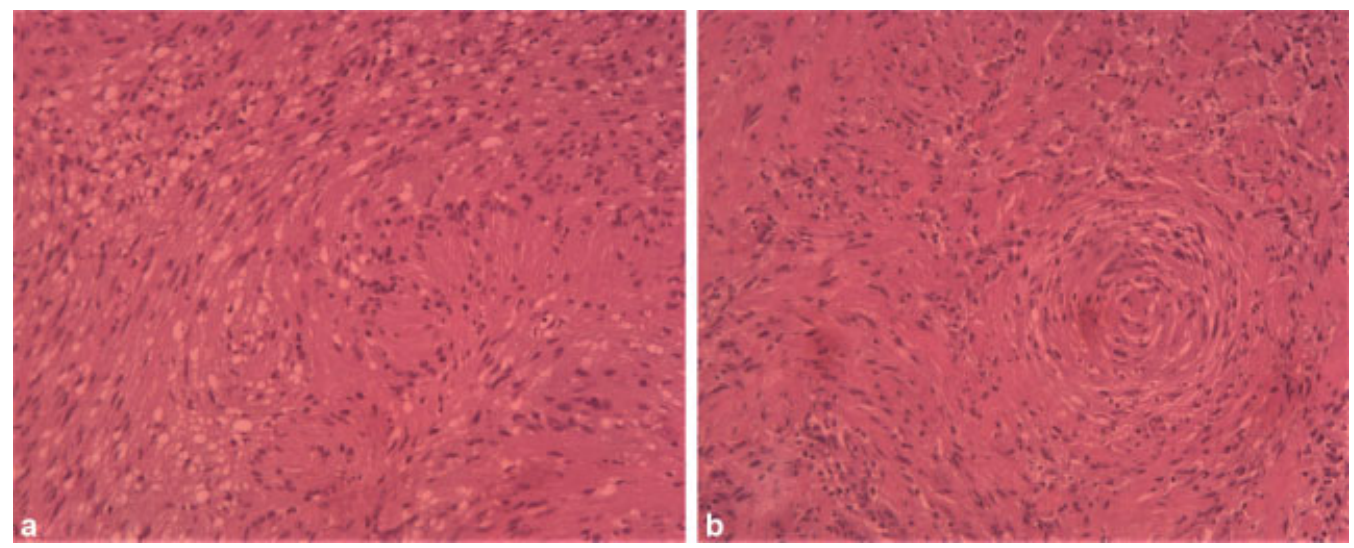

Fig. 4 Second histopathological examination, also conclusive for schwannoma. (a) Hematoxylin \& Eosin stain (5x) - neoplasia consisting of fusocellular cells, Antoni A and Antoni B areas. (b) Hematoxylin \& Eosin stain (10x) - neoplasia consisting of fusocellular and monomorphic cells, without atypia and without presence of mitosis.

approach for total resection of the sphenoidal portion of this lesion. The histopathologic examination was conclusive for schwannoma. The postoperative MRI showed the total resection of this portion, leaving just the orbital portion (-Fig. 2). After 2 years, the patient started to complain about pain in the trajectory of the ophthalmic branch of the trigeminal root and was submitted to a transconjunctival approach for resection of the orbital lesion, combined with an orbital reconstruction (-Fig. 3). The histopathologic examination was also conclusive for schwannoma
(-Fig. 4). After this procedure, the patient became asymptomatic, with no referred facial pain, and without new deficits.

\section{Discussion}

According to the 2016 World Health Organization Classification of Tumors of the Central Nervous System, schwannomas include cellular, plexiform, and melanotic schwannomas, neurofibromas, perineuriomas, hybrid nerve sheath tumors 
and malignant peripheral nerve sheath tumors. ${ }^{11}$ They affect adults in the $3^{\text {rd }}$ to the $7^{\text {th }}$ decades of life ${ }^{12}$ but are more commonly found in patients in their $4^{\text {th }}$ decade, without sex predilection..$^{13}$ This type of tumor comprises the fourth most common primary neoplasm affecting the brain and cranial nerves. ${ }^{14}$ The majority ( $~ 90 \%$ ) of cranial nerve schwannomas arise from the vestibulocochlear nerve, with the next most commonly involved nerves being the trigeminal and facial nerves, followed by the lower cranial nerves. ${ }^{15}$ The orbital nerves more commonly involved are the supratrochlear and supraorbital nerves. ${ }^{16}$

Schwannomas constitute 1 to $8 \%$ of all head and neck tumors. ${ }^{17}$ When intraorbital, it is a rare tumor that accounts for $\sim 1$ to $2 \%$ of all neoplasms of the orbit. ${ }^{4,6}$ They are known to originate from sympathetic and parasympathetic fibers, as well as from branches of the oculomotor, trochlear, trigeminal, and abducens nerves, with the ophthalmic division of the trigeminal nerve being the most common. ${ }^{18}$ Trigeminal schwannomas are particularly rare, accounting for 0.07 to $0.3 \%$ of all intracranial tumors and 0.8 to $5 \%$ of intracranial schwannomas. Orbital schwannomas, most commonly, arise from the sensory branches of the trigeminal nerve. ${ }^{4}$ They may arise from the cisternal segment (most commonly), the trigeminal/Gasserian ganglion in Meckel's cave, or from one of the three branches of the nerve. They tend to occur predominantly in the 4th to 6th decades of life and are slightly more common in females. ${ }^{7}$ The oculomotor, ciliary, lacrimal, and zygomaticotemporal nerves have been reported as the nerves that the orbital schwannomas most commonly arise from. ${ }^{17}$ The frontal nerve, in particular, is frequently affected due to the predominance of sensory nerve branches, namely the supraorbital and supratrochlear nerve. ${ }^{17,18}$ Based on the work of Erdogmus et al, Irace et al proposed that the entry point of nerve fibers in the muscle (e. g., area nervosa or myoneural junction) is the zone where intraorbital schwannomas truly arise. ${ }^{4}$ Motor root and sympathetic chain involvement is uncommon, and involvement of the brain or cord parenchyma is rare. ${ }^{1}$ Also, it is unusual for orbital schwannomas to arise from extraocular muscles, with only a few reports in the literature to date. ${ }^{12}$

Schwannomas are benign tumors consisting of a clonal population of Schwann cells, which often undergo cystic and degenerative change. ${ }^{1}$ They originate in a zone of transition of peripheral central myelin (Obersteiner-Redlich zone $)^{19}$ and are usually isolated, solitary, slow-growing, and wellencapsulated lesions, except when they are associated with neurofibromatosis. In the latter case, the patients can develop multiple schwannomas, in which case the condition is termed schwannomatosis. ${ }^{13}$ Persons with neurofibromatosis type 2 characteristically develop bilateral vestibular schwannomas, but approximately half of them also have nonvestibular schwannomas, which most commonly involve the oculomotor and trigeminal nerves. ${ }^{15}$ Although hereditary disorders predispose to nerve sheath tumors, the specific etiologies of schwannoma remain unknown. However, sporadic reports have suggested an association of formation of schwannomas with previous events of trauma. ${ }^{13}$ Postradiation schwannomas, including acoustic schwannomas, appear with a latency of up to 50 years following treatment. ${ }^{1}$ Besides, they are generally known to be slow-growing, benign masses. There have been clinical reports of rapidly growing schwannomas in pregnant women, attributed to progesterone receptors or intratumoral hemorrhage. ${ }^{12}$

When the imaging features and clinical signs are compatible with schwannoma, the presence of end organ compromise, such as denervation-induced muscle atrophy or sensory deficit, may aid in the identification of the cranial nerve $(\mathrm{CN})$ of origin. ${ }^{15}$ Since most of the tumors originate from the sensory nerves, they do not interfere with the eye movements or vision unless they are located in the orbital apex or compress the optic nerve. ${ }^{17}$ Clinically, trigeminal schwannomas usually present with facial pain, numbness, and paresthesia in the distribution of one or all the divisions of the trigeminal nerve depending on the location of the tumor, ${ }^{7,9,10}$ what seems to fit in our case report. Headache and diplopia can also be present. ${ }^{20}$ Longstanding tumors may also present with motor symptoms like difficulty in chewing and deviation of the jaw. ${ }^{7}$ Yoshida and Kawase showed $6.3 \%$ of asymptomatic patients (found incidentally). ${ }^{21}$

Both MR and CT images show evidence of the slow growth of schwannomas, including smooth expansion of the neural foramina, osseous remodeling, and/or deformation of adjacent brain tissue, with a disproportionately small amount of edema, given the size of the lesion. ${ }^{15}$ Schwannomas have a characteristic appearance on MR imaging: on T2-weighted images, schwannomas appear heterogeneously hyperintense. ${ }^{4,15,22,23}$ This heterogeneity is attributed to regions of compactly arranged cells (Antoni type A) mixed with regions of loosely arranged cells (Antoni type $B$ ), with variable cellularity and water content. ${ }^{15}$ Usually, the central enhancement seems to represent the presence of hypercellular Antoni A-type cells in the central part of the tumor and hypocellular Antoni B-type cells in the periphery. ${ }^{24}$ On T1-weighted images, these lesions have low or intermediate signal intensity and demonstrate avid enhancement after contrast material administration, with or without nonenhancing cystic spaces. Larger lesions commonly have heterogeneous enhancement, cystic spaces, and foci of hemosiderin due to internal hemorrhage. ${ }^{15}$ On CT scan, they usually appear as uniformly enhancing masses with remodeling of the adjacent bone. ${ }^{7,10}$

Several classification systems have been proposed for a systematic approach in selecting the optimal surgical strategy. The most apt system was proposed by Wanibuchi et al based on 4 anatomical categories of tumor: peripheral, ganglion, root, and dumbbell. The peripheral type refers to tumor along V1 in the orbit, V2 in the pterygopalatine fossa (PPF) and maxilla, and V3 into the infratemporal fossa. ${ }^{20,25}$ The Gasserian ganglion was the most frequent site described by Wanibuchi et al, and the most common type of extracranial extension (possibly corresponding peripheral or dumbbell by this classification) was from the third division described by Goel et al. ${ }^{20,26}$

Standard treatment for schwannomas consists of complete surgical resection, whereas subtotal resection is linked to an increased risk of recurrence, ${ }^{25}$ which could reach 13 - 
fold higher. ${ }^{23,27}$ Nevertheless, total tumor removal is not always feasible without neurological complications. In this circumstance, stereotactic radiation technique has emerged as an alternative treatment to surgical resection. ${ }^{25,28}$ This has been shown to provide 5-year progression-free survival of $95 \%$ in selected patients. ${ }^{25}$ With improvement of advanced surgical technique, total tumor removal is accomplished in 40 to $80 \%$ (Sharma et al, 2008; Zhang et al, 2009) of the cases, with tumor control rate of 81 to $100 \%$ (Lee et al, 2001; AlMefty et al, 2002; Goel et al, 2003; Kadri et al, 2004; Bulsara et al, 2008). ${ }^{28}$ Surgical resection is also the best treatment for orbital schwannomas. Subciliary approach is the most preferred method for the masses inferior and medial to the optic nerve. ${ }^{17}$ To access the medial inferior quadrant of the orbit, one option is endoscopic access, which is less invasive than the transcranial route. For small lesions located in the anterior half of the orbit, approaches without osteotomies, like eyelid superiorly or subciliary and orbital rim inferiorly can be tried, but anterior approaches give a restricted vision field, which promotes difficulties in locating and preserve the anatomical structures. ${ }^{2,5,29}$

Even so, the surgical approach must be determined case by case. Raza et al showed results suggesting that endoscopic transpterygoid approaches can help to achieve optimal resection rates with limited $\mathrm{CN}$ morbidity for tumors isolated to the Meckel's cave, with combined Meckel's cave peripheral extension, or primarily extracranial in location. According the Raza et $\mathrm{al}^{25}$, endoscopic transpterygoid approaches provide safe access to Meckel's cave and disease extending along V2 into the Pterygopalatine fossa (PPF) and V3 into the infratemporal fossa without risking additional $\mathrm{CN}$ morbidity. ${ }^{25}$ When complete resection is not possible, adjuvant radiotherapy can be considered. ${ }^{2}$ The authors also reported significant rates of dry eye and corneal neurotrophic keratopathy that should be considered in those patients with either preoperative V1 neuropathy or tumor extending along this division. The presumed mechanism of these complications would be attributable to either vidian nerve injury (if the vidian is transected) or a V1 neuropathy. While an endoscopic transpterygoid approach to Meckel's cave is typically supravidian and does not require the nerve's sacrifice, transposition of the PPF contents could theoretically result in vidian nerve injury. ${ }^{25}$ Pain (>90\% of the patients), dysesthesia, and diplopia may be relieved after surgery; however, hypesthesia frequently remains or may be worsened by surgery. ${ }^{20}$

\section{Conclusion}

Schwannomas are benign and highly treatable lesions. When trigeminal, from the ophthalmic branch, they are extremely rare lesions, usually obeying the symptomatology of the nerve path. The approach should be individualized according to the morphology of the lesions and nerve involvement, always looking for total resection or subtotal in association with radiation therapy.

\section{Conflict of Interests}

The authors declare that there is no conflict of interests.

\section{References}

1 Hilton DA, Hanemann CO. Schwannomas and their pathogenesis. Brain Pathol 2014;24(03):205-220. Doi: 10.1111/bpa.12125

2 Caramanti RL, Goes MJ, Chaddad F, et al. Orbital Schwannoma: Case Report and Review. Arq Bras Neurocir Brazilian Neurosurg. 2019:10-13. Doi: 10.1055/s-0039-1693683

3 Mahore A, Ramdasi R, Chagla A, Tikeykar V. Intraconal optic sheath schwannoma: report of two cases. Br J Neurosurg 2019; 33(01):101-103

4 Iida Y, Sakata K, Kobayashi N, Tatezuki J, Manaka H, Kawasaki T. Orbital Abducens Nerve Schwannoma: A Case Report and Review of the Literature. NMC Case Rep J 2016;3(04):107-109. Doi: 10.2176/nmccrj.cr.2015-0259

5 Montano N, Lauretti L, D’Alessandris QG, et al. Orbital Tumors: Report of 70 Surgically Treated Cases. World Neurosurg 2018; 119:e449-e458. Doi: 10.1016/j.wneu.2018.07.181

6 Wang Y, Xiao LH. Orbital schwannomas: findings from magnetic resonance imaging in 62 cases. Eye (Lond) 2008;22(08):1034-1039. Doi: 10.1038/sj.eye.6702832

7 Agarwal A. Intracranial trigeminal schwannoma. Neuroradiol J 2015;28(01):36-41. Doi: 10.15274/NRJ-2014-10117

8 Pollack IF, Sekhar LN, Jannetta PJ, Janecka IP. Neurilemomas of the trigeminal nerve. J Neurosurg 1989;70(05):737-745. Doi: 10.3171/jns.1989.70.5.0737

9 Borges A, Casselman J. Imaging the trigeminal nerve. Eur J Radiol 2010;74(02):323-340. Doi: 10.1016/j.ejrad.2010.02.006

10 Bathla G, Hegde AN. The trigeminal nerve: an illustrated review of its imaging anatomy and pathology. Clin Radiol 2013;68(02): 203-213. Doi: 10.1016/j.crad.2012.05.019

11 Louis DN, Perry A, Reifenberger G, et al. The 2016 World Health Organization Classification of Tumors of the Central Nervous System: a summary. Acta Neuropathol 2016;131(06):803-820. Doi: 10.1007/s00401-016-1545-1

12 Young SM, Kim YD, Hwang SS, Woo KI. Orbital Schwannoma With Atypical Presentation. J Craniofac Surg 2018;29(03):e224-e226. Doi: $10.1097 /$ SCS.0000000000004177

13 Albert P, Patel J, Badawy K, et al. Peripheral Nerve Schwannoma: A Review of Varying Clinical Presentations and Imaging Findings. J Foot Ankle Surg 2017;56(03):632-637. Doi: 10.1053/j. jfas.2016.12.003

14 Strowd RE III, Blakeley JO. Common Histologically Benign Tumors of the Brain. Continuum (Minneap Minn) 2017;23(06Neurooncology1680-1708. Doi: 10.1212/CON.0000000000000541

15 Skolnik AD, Loevner LA, Sampathu DM, et al. Cranial Nerve Schwannomas: Diagnostic Imaging Approach. Radiographics 2016;36(05):1463-1477. Doi: 10.1148/rg.2016150199

16 Kim KS, Jung JW, Yoon KC, Kwon YJ, Hwang JH, Lee SY. Schwannoma of the Orbit. Arch Craniofac Surg 2015;16(02):67-72. Doi: 10.7181/acfs.2015.16.2.67

17 Tezer MS, Ozcan M, Han O, Unal A, Ozlugedik S. Schwannoma originating from the infraorbital nerve: a case report. Auris Nasus Larynx 2006;33(03):343-345. Doi: 10.1016/j.anl.2005.11.015

18 Young SM, Kim YD, Jeon GS, Woo KI. Orbital Frontal Nerve Schwannoma-Distinctive Radiological Features. Am J Ophthalmol 2018;186:41-46. Doi: 10.1016/j.ajo.2017.11.012

19 Madrid-Sánchez AJ, Castillo-Rangel C, Contreras-Ayala ML, RuizGarcía E, Castillo-Castro AK, Ramírez-Aguilar R. Schwannoma trigeminal maxilar. Presentación de un caso y revisión de la literatura. Cir y Cir (English Ed) 2017;85(01):49-52. Doi: 10.1016/j.circir.2016.11.008

20 MacNally SP, Rutherford SA, Ramsden RT, Evans DG, King AT. Trigeminal schwannomas. Br J Neurosurg 2008;22(06):729-738. Doi: $10.1080 / 02688690802272172$

21 Yoshida K, Kawase T. Trigeminal neurinomas extending into multiple fossae: surgical methods and review of the literature. J Neurosurg 1999;91(02):202-211. Doi: 10.3171/jns.1999.91.2.0202

22 Xu F, Pan S, Alonso F, Dekker SE, Bambakidis NC. Intracranial Facial Nerve Schwannomas: Current Management and Review of 
96 Trigeminal Ophthalmic Branch Schwannoma Köhler et al.

Literature. World Neurosurg 2017;100:444-449. Doi: 10.1016/j. wneu.2016.09.082

23 Petersen J, Gilain L, Coutu A, Saroul N. Frontal sinus schwannoma. Eur Ann Otorhinolaryngol Head Neck Dis 2018;135(03):213-215. Doi: 10.1016/j.anorl.2018.03.001

24 Karaman İ, Öner M, Kafadar IH, Güney A, Argun M. Surgical excision of peripheral nerve schwannomas: analysis of 11 patients. Acta Orthop Traumatol Turc 2015;49(02):139-143. Doi: 10.3944/AOTT.2015.14.0119

25 Raza SM, Donaldson AM, Mehta A, Tsiouris AJ, Anand VK, Schwartz TH. Surgical management of trigeminal schwannomas: defining the role for endoscopic endonasal approaches. Neurosurg Focus 2014;37(04):E17. Doi: 10.3171/2014.7.FOCUS14341

26 Goel A, Shah A, Muzumdar D, Nadkarni T, Chagla A. Trigeminal neurinomas with extracranial extension: analysis of 28 surgically treated cases. J Neurosurg 2010;113(05):1079-1084. Doi: 10.3171/2009.10.JNS091149

27 Jacob JT, Carlson ML, Driscoll CL, Link MJ. Volumetric analysis of tumor control following subtotal and near-total resection of vestibular schwannoma. Laryngoscope 2016;126(08):1877-1882. Doi: 10.1002/lary.25779

28 Puataweepong P, Dhanachai M, Hansasuta A, et al. Clinical outcomes of intracranial nonvestibular schwannomas treated with linac-based stereotactic radiosurgery and radiotherapy. Asian Pac J Cancer Prev 2016;17(07):3271-3276. Doi: $10.1093 / \mathrm{jrr} / \mathrm{rrt} 235$

29 Bachelet JT, Shipkov H, Breton P, Berhouma M, Jouanneau E, Gleizal A. [Surgical approaches of tumors of the posterior cone of the orbit]. Rev Stomatol Chir Maxillofac Chir Orale 2016;117 (02):89-95. Doi: 10.1016/j.revsto.2016.01.005 